\title{
COVID- 19-Related Variables and Its Association with Anxiety and Suicidal Ideation: Differences Between International and Local University Students in Taiwan
}

\author{
Daniel Kwasi Ahorsu (iD) ${ }^{1, *}$ \\ lqbal Pramukti ${ }^{2, *}$ \\ Carol Strong ${ }^{3}$ \\ Hsiao-Wen Wang ${ }^{4}$ \\ Mark D Griffiths $\left.{ }^{5}\right)^{5}$ \\ Chung-Ying Lin $\mathbb{D I}^{3,6-8}$ \\ Nai-Ying Ko ${ }^{9}$
}

'Department of Rehabilitation Sciences, Faculty of Health \& Social Sciences, The Hong Kong Polytechnic University, Hung Hom, Hong Kong;

${ }^{2}$ Faculty of Nursing, Universitas Padjadjaran, West Java, Indonesia; ${ }^{3}$ Department of Public Health, College of Medicine, National Cheng Kung University, Tainan, Taiwan; ${ }^{4}$ Department of Hydraulic and Ocean Engineering, National Cheng Kung University, Tainan, 70I, Taiwan; International Gaming Research Unit, Psychology Department, Nottingham Trent University, Nottingham, UK; ${ }^{6}$ Institute of Allied Health Sciences, College of Medicine, National Cheng Kung University, Tainan, Taiwan; ${ }^{7}$ Department of Occupational Therapy, College of Medicine, National Cheng Kung University, Tainan, Taiwan; ${ }^{8}$ Biostatistics Consulting Center, National Cheng Kung University Hospital, College of Medicine, National Cheng Kung University, Tainan, Taiwan; ${ }^{9}$ Department of Nursing, College of Medicine, National Cheng Kung University, Tainan, Taiwan

*These authors contributed equally to this work

Correspondence: Chung-Ying Lin Institute of Allied Health Sciences and Departments of Occupational Therapy and Public Health, Biostatistics Consulting Center, National Cheng Kung University Hospital, College of Medicine, National Cheng Kung University, I

University Road, Tainan, 70I, Taiwan

Tel +886-6-2353535-5106

Fax +886-6-236798

Email cylin36933@gmail.com

Correspondence: Nai-Ying Ko

Department of Nursing, College of Medicine,

National Cheng Kung University, I University

Road, Tainan, 70I, Taiwan

Tel +886-6-2353535-5838

Fax +886-6-2377550

Email nyko@mail.ncku.edu.tw
Purpose: The present study examined the differences between international and local university students in Taiwan regarding COVID-19-related variables, anxiety, and suicidal ideation.

Participants and Methods: An online cross-sectional survey (sent via an online link in an email) was carried out comprising university students $(n=529)$. The students were assessed on measures (including validated psychometric instruments) of perceived susceptibility to COVID-19, perceived sufficiency of resources, sources of COVID-19 information, perceived satisfaction with support, anxiety and suicidal ideation.

Results: Local students had higher susceptibility to COVID-19 $(p<0.001)$ but decreased sufficiency with resources $(p<0.001)$ and anxiety $(p<0.001)$ compared with international students. Staying with family members, satisfaction with support, and information seeking were the factors that predicted anxiety among international students (all $p$-values $<0.05$ ), while information seeking predicted local students' anxiety $(p<0.001)$. Furthermore, staying with family members, susceptibility to COVID-19, and sufficiency with resources were the factors that predicted suicidal ideation among international students (all $p$-values $<0.05$ ), while being a male and satisfaction with support predicted suicidal ideation among local students (all $p$-values $<0.05$ ).

Conclusion: International students displayed different COVID-19-related challenges compared with local students. More specifically, international students as compared with local students had lower susceptibility to COVID-19 and higher anxiety. Therefore, healthcare providers should pay more attention to international students' psychological health and awareness regarding impacts of COVID-19 on health.

Keywords: anxiety, COVID-19, university students, suicidal ideation, Taiwan

\section{Plain Language Summary}

The present study was carried out in order to examine the differences of COVID-19-related issues (including psychological distress such as anxiety and suicidal ideation) between international and local university students who were studying in Taiwan during the COVID-19 pandemic. The study recruited 529 university students and they responded to questions concerning perceived susceptibility to COVID-19, perceived sufficiency of resources, sources of COVID-19 information, perceived satisfaction with support, anxiety, and suicidal thoughts. The results indicated that:

1. Local students had higher levels of susceptibility to COVID-19 but decreased sufficiency with resources and anxiety compared with international students. 
2. Staying with family members, satisfaction with support, and information seeking were the factors that predicted anxiety among international students while information seeking predicted local students' anxiety.

3. Staying with family members, susceptibility to COVID19 , and sufficiency with resources were the factors that predicted suicidal ideation among international students while being a male and satisfaction with support predicted suicidal ideation among local students.

Overall, international students displayed different COVID19-related challenges compared with local students.

\section{Introduction}

The coronavirus disease 2019 (COVID-19) continues to ravage the world with significant adverse effects on human life. There were over 231 million cases of COVID-19 infection and over 4.7 million deaths worldwide as of September 24, 2021. ${ }^{1}$ This pandemic has negatively affected individuals' way of life causing serious economic, $^{2-4}$ social, $^{5,6}$ and health ${ }^{7-12}$ challenges worldwide. Several notable mandatory short-term measures such as physical distancing, lockdowns, use of face masks, and washing of hands have been used by different countries to mitigate the spread of COVID-19. ${ }^{13,14}$ These measures are still being used even though some vaccines have been approved to help mitigate the spread of COVID-19 infection. These short-term measures (eg, lockdowns, physical distancing, and quarantining) have markedly affected the health and activities of individuals, ${ }^{8,15,16}$ and especially students. ${ }^{11,17,18}$

The volatile nature of the disease has led to rapidly evolving change of information and policies concerning COVID-19. This has sensitized many individuals to diligently follow and be updated on COVID-19-related issues especially among those susceptible to COVID-19 or those significantly affected by the COVID-19 pandemic such as students. Those who are perceived as being susceptible to COVID-19 are individuals that have higher likelihoods of contracting COVID-19. Therefore, providing accurate information regularly, and having robust and reassuring policies helps to allay fears among these individuals. Consequently, the source of COVID-19 information must be credible, of good quality, and be from a trusted source in order to help overcome COVID-19. ${ }^{19-22}$ It has been reported that poorly managed communication may lead to social withdrawal, hysteria, individual violence, and

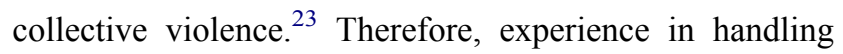

pandemic information is key to appropriately deal with the pandemic. Younger or inexperienced individuals have been found to poorly manage information or cope with challenging situations and as a result, have mental health challenges. ${ }^{17,24,25}$

Furthermore, young individuals (who are mostly students and specifically university students) have been reported to have added pressure of dealing with academic challenges and future job prospects/internships during the COVID-19 pandemic. ${ }^{17,26}$ Consequently, university students have been found to have severe mental health disorders (eg, fear, stress, anxiety, depression), poorer physical fitness, and poorer academic performance during the pandemic. ${ }^{11,17,18}$ Furthermore, studies have highlighted strong associations between COVID-19-related variables such as fear of COVID-19 and anxiety, depression, and self-esteem. ${ }^{27,28}$ This is important to note because depression, stress, and self-esteem are strongly associated with suicidal ideation among students ${ }^{24}$ especially when ineffective or maladaptive coping strategies are used. ${ }^{28}$ Anxiety, as used in the present study, involves how worried or nervous individuals are toward COVID-19 while suicidal ideation refers to thoughts regarding suicide among individuals. ${ }^{29}$ As a result of these challenges, most of these students depend on their close families, friends, and faculty for support in dealing with COVID-19. The support may include personal protective equipment (PPE), information, money, medical resources, and psychological support. Therefore, satisfaction with the support and the sufficiency of these resources in combating COVID-19 may help in reducing students' fear and frustration, ultimately improving their mental health. ${ }^{19}$

The impact of COVID-19 is not very different in Taiwan (where the present study was carried out) although there have been comparatively fewer cases and fatalities reported. As of September 24, 2021, over 16,000 COVID19 cases and over 840 fatalities had been recorded. ${ }^{30}$ To date, the success of managing and containing the virus has been attributed to a combination of two agents, the government and the citizens. More specifically, this involved the government's swift activation of the Central Epidemics Command Center, transparent and open communication regarding COVID-19, short-term measures taken to curtail the spread, and measures introduced to lessen the challenges its citizens may go through. ${ }^{31}$ Therefore, Taiwanese citizens did not just receive correct and timely information but also received supportive and encouraging messages, substantially lessening their fear and anxiety. In return, 
Taiwanese citizens understood the need to accommodate these difficult changes and complied with the COVID-19 policies resulting in comparatively lower cases than other countries. $^{22,32}$ Nonetheless, lockdowns, physical distancing, and quarantining have been reported to be associated with poor health and quality of life $\mathrm{e}^{16,33,34}$ and students in Taiwan are not exempt from these challenges. ${ }^{20,35}$ However, compared to other countries, Taiwanese students have been found to have the lowest levels of mental health issues (eg, anxiety, suicidal ideation) ${ }^{19,36}$ which is assumed to be due to the early reaction by the Taiwan government to control the spread of COVID-19. ${ }^{22}$

Because there are heterogeneous groups of university students (eg, international vs. local students), it is appropriate that their perception concerning factors related to COVID-19 are thoroughly examined in order to understand and offer tailored help during COVID-19 pandemic. This is more important because Taiwan has different policies in combating the spread of COVID-19 and has been successful so far. However, given that these policies significantly change individuals' way of life in order to manage the COVID-19 pandemic, there is a need to both ascertain and understand the consequences of these abrupt changes in order to provide appropriate recommendations to the relevant authorities. Therefore, the present study examined the differences between international and local students residing in Taiwan on issues related to perceived susceptibility to COVID-19, sufficiency of resources, information seeking, satisfaction with support, and mental health (ie, anxiety and suicidal ideation) during COVID-19 outbreak period.

\section{Methods}

\section{Participants and Procedure}

A convenience sample of 529 university students were recruited for a cross-sectional survey study in Taiwan. The sample comprised international and local students. The recruitment of the participants was carried out online via students' university email addresses from April to June 2020. The participants were eligible for the present study if they were $\geq 20$ years old and studied at university in Taiwan. The participants were asked to login through their personal email before completing the questionnaire.

Ethical approval was obtained from the Institute of Review Board from National Cheng Kung University Hospital (A-EX-109-019) prior to data collection. Participation was voluntary and survey responses were anonymous; therefore, the Research Ethics Committee ruled that this study did not require informed consent. The following details were provided in on the online form: the name of the investigator, the study purpose, and the privacy rights of the participants. Study participants were given no incentives for participation. Those who agreed to participate in the study completed the survey in English (for international students) or Chinese languages (for local students). The survey was first developed in English with guidance from the extant literature. Following this, a bilingual translator whose mother tongue was Chinese translated the English survey into Chinese. The two language versions of the online survey were hosted on Google Forms. Therefore, different links were sent out for the two target populations. More specifically, the international students received a link to the English online survey and the local students received a link to the Chinese online survey. However, both surveys consisted of the same psychometric scales, measures and questions.

Information regarding the students' university email addresses and whether the students were local students or international students were obtained from the university. Emails containing the link to the online survey were then sent according to the student status (ie, local or international student). Students were explicitly asked to complete the survey once. The present study was conducted in accordance with the Declaration of Helsinki.

\section{Measures}

The online survey comprised four measures as the independent variables (perceived susceptibility to COVID-19, perceived sufficiency of resources, source of COVID-19 information, and perceived satisfaction of support) and two measures as the dependent variables (anxiety and suicidal ideation). The survey began with a set of demographic questions, followed by the core items of the survey. At the end of the survey, the participants were given the unique link containing professional advice on epidemic prevention provided by professional medical institutions.

\section{Demographic Characteristics}

Demographic data including age, gender, type of student (international or local), and education level were collected using a background information sheet.

\section{Perceived Susceptibility to COVID-19}

The Perceived Susceptibility to COVID-19 Scale $^{37}$ was used to assess the absolute and relative susceptibility to 
COVID-19. Participants are asked to estimate their personal likelihood of contracting COVID-19 in the coming months. The two-item scale is rated on a 7-point scale from 1 ("not at all susceptible") to 7 ("very susceptible"). It has been used among university students in Taiwan with acceptable psychometric properties. ${ }^{19}$ It had adequate internal reliability in the present study (Cronbach's alpha $[\alpha]=0.61)$.

\section{Perceived Sufficiency of Resources}

The Perceived Sufficiency of Resources Scale ${ }^{19}$ was used to assess the resources needed for preventing COVID-19. Its items include perceived sufficiency of personal protective equipment (PPE), information, money, medical resource, and psychological support. The five-item scale is rated on a 3-point scale from 1 ("insufficient") to 3 ("sufficient"). It has been used among university students in Taiwan with acceptable psychometric properties. ${ }^{19}$ It had acceptable internal reliability in the present study $(\alpha=0.76)$.

\section{Sources of COVID-19 Information}

The Sources of COVID-19 Information Scale ${ }^{19}$ was used to assess various sources from which individuals can access information concerning COVID-19. Its items include seeking information from the internet, friends, news media, academic training, medical staff, faculty/university, and family. The seven-item scale is rated on a 3-point scale from 1 ("never") to 3 ("always"). The scale has been used among university students in Taiwan with acceptable psychometric properties. ${ }^{19}$ It had acceptable internal reliability in the present study $(\alpha=0.67)$.

\section{Perceived Satisfaction with Support}

The Perceived Satisfaction with Support Scale ${ }^{19}$ was used to assess how satisfied individuals are with the various types of support received. Its items include support from families, friends, and faculty. The three-item scale is rated on a 5-point scale from 1 ("not satisfied at all") to 5 ("very satisfied"). This scale has been used among university students in Taiwan with acceptable psychometric properties. ${ }^{19,38}$ It had acceptable internal reliability in the present study $(\alpha=0.70)$.

\section{Anxiety}

Participants' level of anxiety towards the COVID-19 pandemic was assessed using the State-Trait Anxiety Inventory. ${ }^{39}$ Items include feeling "rested," “content," "comfortable," "relaxed," "pleasant," “anxious," "nervous," "jittery," "high strung," and "over-excited and rattled." This 10-item scale is rated on a 4-point scale from 1 ("not at all") to 4 ("very much"). A lower score on the STAI indicates a lower level of anxiety. This scale has been used among university students in Taiwan with acceptable reliability $(\alpha=0.66) .{ }^{19}$ It had acceptable internal reliability in the present study $(\alpha=0.72)$.

\section{Suicidal Ideation}

Participants' level of suicidal ideation in the past week was assessed using one item (ie, "In the past seven days, did you have a suicidal idea") rated a 5-point scale from 1 ("not at all") to 5 ("very severe"). A lower score on this scale indicates a lower level of suicidal ideation. ${ }^{19}$

\section{Data Analysis}

Descriptive analyses including means (and standard deviations) and frequencies (percentages) were used to present the proportions of demographic variables of the participants. The chi-square test and independent $t$-test were used to compare the proportions in categorical and continuous variables, respectively. Also, the independent $t$-test was used to examine the significant between-group difference on perceived susceptibility to COVID-19, perceived satisfaction with support, perceived sufficiency with resources, information seeking, anxiety, and suicidal ideation. Multiple linear regression was used to examine the factors on anxiety and suicidal thoughts separately for international and local students in Taiwan.

\section{Results}

A total of 529 participants were used in the present study with a mean age of 25.70 years $(\mathrm{SD}=6.00)$, the majority being females $(59.1 \%)$, undergraduates $(58.4 \%)$, not staying with family (86.6\%), and medical students (54.4\%). Apart from gender, these variables were significantly more than their counterparts $(p$-values $<0.001)$. The participants were made up of international $(\mathrm{n}=216)$ and local (Taiwan; $\mathrm{n}=313$ ) students with their mean ages being 28.45 years $(\mathrm{SD}=6.41)$ and 23.85 years $(\mathrm{SD}=4.91)$ respectively. Further demographic information is shown in Table 1.

Table 2 shows that the local students $(6.95 \pm 1.92)$ had more significant scores than international $(5.90 \pm 2.16)$ students on perceived susceptibility to COVID-19 ( $t(527)$ $=5.86, p<0.001)$. However, international students $(7.26 \pm$ 2.14) had more significant scores than local students $(6.00$ $\pm 1.57)$ on their perceived sufficiency with resources $(t$ 
Table I Participants' Characteristics

\begin{tabular}{|c|c|c|c|c|}
\hline & Total $(n=529)$ & International Students $(n=2 \mid 6)$ & Local Students $(n=3 \mid 3)$ & $p$ \\
\hline Age; Mean $\pm S D$ & $25.70 \pm 6.00$ & $28.45 \pm 6.41$ & $23.85 \pm 4.91$ & $<0.001$ \\
\hline Gender; n (\%) & & & & 0.068 \\
\hline Females & $311(59.1 \%)$ & $117(22.2 \%)$ & $194(36.9 \%)$ & \\
\hline Males & $215(40.9 \%)$ & $98(18.6 \%)$ & $117(22.2 \%)$ & \\
\hline Education; n (\%) & & & & $<0.001$ \\
\hline Undergraduates & $309(58.4 \%)$ & $33(6.2 \%)$ & $276(52.2 \%)$ & \\
\hline Postgraduates & $220(41.6 \%)$ & $183(34.6 \%)$ & $37(7.0 \%)$ & \\
\hline Residency; n (\%) & & & & $<0.001$ \\
\hline Not with family & $458(86.6 \%)$ & $211(39.9 \%)$ & $247(46.7 \%)$ & \\
\hline With family & $7 \mid(13.4 \%)$ & $5(0.9 \%)$ & $66(12.5 \%)$ & \\
\hline Student; n (\%) & & & & $<0.001$ \\
\hline Medical & $24 I(45.6 \%)$ & $161(30.4 \%)$ & $80(15.1 \%)$ & \\
\hline Non-medical & $288(54.4 \%)$ & $55(10.4 \%)$ & $233(44.0 \%)$ & \\
\hline
\end{tabular}

$(527)=7.80, p<0.001)$. Also, international students $(2.24 \pm$ $0.43)$ had more significant scores than local students $(1.17$ $\pm 0.52)$ on anxiety $(t(527)=4.34, p<0.001)$. However, there was no significant between-group difference on perceived satisfaction with support $(t(527)=0.10, p=924)$, information seeking $(t(527)=0.26, p=0.798)$, and suicidal ideation $(t(527)=0.50, p=0.617)$.

After controlling for age and student (medicine), it was found that residence (with family; standardized coefficient $[\beta]=-0.222, p<0.001)$, perceived satisfaction with support $(\beta=0.164, p=0.021)$, and information seeking $(\beta=0.270$, $p<0.001)$ were the significant factors that predicted anxiety among international students in Taiwan. Among the local students in Taiwan, information seeking $(\beta=0.228$, $p<0.001$ ) was the only significant factor that predicted anxiety after controlling for age and student (medicine).
In total, the factors accounted for $19 \%$ and $7.6 \%$ of all factors needed for predicting anxiety among the international students $[F(9,200)=5.204, p<0.001]$ and local students $[F(6,300)=2.743, p=0.004]$ in Taiwan respectively. Further details are shown in Table 3.

Table 4 shows that residence (with family; $\beta=0.173$, $p=0.014)$, perceived susceptibility to COVID-19 $(\beta=0.158$, $p=0.020$ ), and perceived sufficiency with resources ( $\beta=0.157, p=0.026$ ) were the significant factors that predicted suicidal ideation among international students after controlling for age and student (medicine). Among the local students in Taiwan, gender (males; $(\beta=-0.122$, $p=0.035)$ ) and perceived satisfaction with support $(\beta=$ $-0.130, p=0.030$ ) were found to be the significant factors that predicted suicidal ideation after controlling for age and student (medicine). In total, the factors accounted for

Table 2 Summary of Analysis Between International and Local Taiwan Students on Anxiety, Suicidal Ideation, and Other Variables on COVID-19

\begin{tabular}{|l|l|l|l|l|}
\hline & International & Local & \multirow{2}{*}{$\boldsymbol{t}$} \\
\cline { 2 - 4 } & Mean \pm SD & Mean \pm SD & \\
\hline Perceived susceptibility to COVID-19 & $5.90 \pm 2.16$ & $6.95 \pm 1.92$ & 5.855 & $<0.001$ \\
Perceived satisfaction with support & $11.69 \pm 2.02$ & $11.68 \pm 2.05$ & 0.095 & 0.924 \\
Perceived sufficiency with resources & $7.26 \pm 2.14$ & $6.00 \pm 1.57$ & 7.800 & $<0.001$ \\
Information seeking & $15.37 \pm 2.80$ & $15.42 \pm 2.48$ & 0.256 & 0.798 \\
Anxiety & $2.24 \pm 0.43$ & $2.08 \pm 0.42$ & 4.343 & $<0.001$ \\
Suicidal ideation & $1.14 \pm 0.49$ & $1.17 \pm 0.52$ & 0.500 & 0.617 \\
\hline
\end{tabular}

Notes: Perceived susceptibility to COVID-19: the likelihood of contracting COVID-19; Perceived satisfaction with support: satisfaction with various supports received; Perceived sufficiency with resources: resources needed for preventing COVID-19; Information seeking: various sources from which individuals can access information on COVID-19: Anxiety: how worried or nervous individuals are toward COVID-19; Suicidal ideation: thoughts of suicide. 
Table 3 Summary of Predictive Factors on Anxiety Between International and Local Students Residing in Taiwan During COVID-19 Outbreak Period

\begin{tabular}{|c|c|c|c|c|c|c|c|c|c|}
\hline & & \multicolumn{4}{|c|}{ International } & \multicolumn{4}{|l|}{ Locals } \\
\hline & & B & SE & B & $p$ & B & SE & B & $p$ \\
\hline \multirow[t]{2}{*}{ Step I } & Age & 0.001 & 0.005 & 0.014 & 0.840 & 0.000 & 0.005 & 0.000 & 0.995 \\
\hline & Student (medicine) & -0.027 & 0.071 & -0.027 & 0.702 & -0.023 & 0.056 & -0.023 & 0.684 \\
\hline \multirow[t]{10}{*}{ Step 2} & Gender (males) & 0.068 & 0.056 & 0.080 & 0.224 & 0.031 & 0.050 & 0.035 & 0.533 \\
\hline & Education (postgraduates) & -0.041 & 0.083 & -0.034 & 0.626 & 0.060 & 0.087 & 0.046 & 0.487 \\
\hline & Residence (with family) & -0.623 & 0.187 & -0.222 & 0.001 & 0.059 & 0.059 & 0.057 & 0.316 \\
\hline & Perceived susceptibility to COVID-19 & -0.019 & 0.013 & -0.095 & 0.142 & -0.001 & 0.013 & -0.005 & 0.940 \\
\hline & Perceived satisfaction with support & 0.035 & 0.015 & 0.164 & 0.021 & 0.021 & 0.012 & 0.102 & 0.082 \\
\hline & Perceived sufficiency with resources & 0.025 & 0.013 & 0.128 & 0.058 & 0.022 & 0.015 & 0.084 & 0.146 \\
\hline & Information seeking & 0.041 & 0.010 & 0.270 & $<0.001$ & 0.039 & 0.010 & 0.228 & $<0.001$ \\
\hline & $\mathbf{R}^{2}$ (adjusted $\mathbf{R}^{2}$ ) & \multirow{3}{*}{\multicolumn{4}{|c|}{$\begin{array}{l}19 \%(15.3 \%) \\
18.9 \% \\
6.664 * * *\end{array}$}} & \multirow{3}{*}{\multicolumn{4}{|c|}{$\begin{array}{l}7.6 \%(4.8 \%) \\
7.5 \% \\
3.501 * *\end{array}$}} \\
\hline & $\Delta \mathbf{R}^{2}$ & & & & & & & & \\
\hline & $\Delta \mathbf{F}$ & & & & & & & & \\
\hline
\end{tabular}

Notes: Perceived susceptibility to COVID-19: the likelihood of contracting COVID-19; Perceived satisfaction with support: satisfaction with various supports received; Perceived sufficiency with resources: resources needed for preventing COVID-19; Information seeking: various sources from which individuals can access information on COVID-19: Anxiety: how worried or nervous individuals are toward COVID-19; Suicidal ideation: thoughts of suicide. $*^{*} p<0.01 . * * * p<0.001$.

$11.4 \%$ and $5.1 \%$ of all factors needed for predicting suicidal ideation among the international students $[F(9,200)$ $=2.852, p=0.003]$ and local students $[F(6,300)=1.807$, $p=0.066]$ in Taiwan, respectively.

\section{Discussion}

The present study examined the differences between international and local students residing in Taiwan regarding perceived susceptibility to COVID-19, sufficiency of resources, information seeking, satisfaction with support, and mental health (ie, anxiety and suicidal ideation) as well as the factors that account for anxiety and suicidal ideation separately among international and local students in Taiwan during the COVID-19 outbreak period. The between-group comparison showed that local students had significantly higher scores on perceived susceptibility

Table 4 Summary of Predictive Factors on Suicidal Ideation Between International and Local Students Residing in Taiwan During COVID-19 Outbreak Period

\begin{tabular}{|c|c|c|c|c|c|c|c|c|c|}
\hline & & \multicolumn{4}{|c|}{ International Students } & \multicolumn{4}{|c|}{ Local Students } \\
\hline & & B & SE & B & $p$ & B & SE & B & $p$ \\
\hline \multirow[t]{2}{*}{ Step I } & Age & -0.007 & 0.006 & -0.084 & 0.239 & -0.003 & 0.006 & -0.030 & 0.600 \\
\hline & Student (medicine) & -0.071 & 0.082 & -0.061 & 0.388 & -0.025 & 0.069 & -0.021 & 0.718 \\
\hline \multirow[t]{10}{*}{ Step 2} & Gender (males) & 0.014 & 0.069 & 0.014 & 0.834 & -0.132 & 0.062 & -0.122 & 0.035 \\
\hline & Education (postgraduates) & -0.007 & 0.102 & -0.005 & 0.946 & -0.002 & 0.109 & -0.001 & 0.987 \\
\hline & Residence (with family) & 0.566 & 0.229 & 0.173 & 0.014 & 0.089 & 0.074 & 0.069 & 0.232 \\
\hline & Perceived susceptibility to COVID-19 & 0.037 & 0.016 & 0.158 & 0.020 & 0.012 & 0.016 & 0.043 & 0.480 \\
\hline & Perceived satisfaction with support & -0.019 & 0.018 & -0.076 & 0.302 & -0.033 & 0.015 & -0.130 & 0.030 \\
\hline & Perceived sufficiency with resources & 0.037 & 0.016 & 0.157 & 0.026 & 0.025 & 0.019 & 0.075 & 0.199 \\
\hline & Information seeking & 0.002 & 0.013 & 0.012 & 0.868 & -0.005 & 0.013 & -0.022 & 0.718 \\
\hline & $\mathbf{R}^{2}$ (adjusted $\mathbf{R}^{2}$ ) & \multirow{3}{*}{\multicolumn{4}{|c|}{$\begin{array}{l}11.4 \%(7.4 \%) \\
10.1 \% \\
3.240 * *\end{array}$}} & \multirow{3}{*}{\multicolumn{4}{|c|}{$\begin{array}{l}5.1 \%(2.3 \%) \\
5 \% \\
2.256 *\end{array}$}} \\
\hline & $\Delta \mathbf{R}^{2}$ & & & & & & & & \\
\hline & $\Delta \mathbf{F}$ & & & & & & & & \\
\hline
\end{tabular}

Notes: Perceived susceptibility to COVID-19: the likelihood of contracting COVID-19; Perceived satisfaction with support: satisfaction with various supports received; Perceived sufficiency with resources: resources needed for preventing COVID-19; Information seeking: various sources from which individuals can access information on COVID-19: Anxiety: how worried or nervous individuals are toward COVID-19; Suicidal ideation: thoughts of suicide. $* p<0.05$. $* * p<0.01$. 
to COVID-19 than international students. However, international students were significantly more anxious compared with local students. Both groups were found to be comparable with respect to perceived satisfaction with support, information seeking, and suicidal ideation. Moreover, different factors were found to predict anxiety and suicidal ideation among local and international students in Taiwan.

The findings concerning perceived susceptibility to COVID-19 indicated that the local students in Taiwan perceived being in absolute or relative danger of contracting COVID-19 compared with international students. A possible reason underlying this significant difference is the greater possibility of contact with an individual with COVID-19 as they have their families, friends, and other significant loved ones around them compared to the international students. Another possible reason is the resources available for protecting an individual against COVID-19 which includes personal protective equipment (PPE), information, money, medical resource, and psychological support. Therefore, it was not surprising that there was a significant between-group difference in perceived sufficiency with resources with international students having more scores than local students. Therefore, it can be assumed that international students had the needed resources to make them feel secured from not contracting COVID-19. This is a novel study with novel findings as other known studies compared different students within their respective countries therefore, the findings are in favor of Taiwanese students due to their successful management of COVID-19 reflected in their lower cases. For instance, Taiwanese students, compared to their counterparts, were found to have lower possibility of contact with an individual with COVID-19 and therefore lesser challenges associated with COVID-19. ${ }^{19,36}$ This supports other studies that reported that sufficient resources such as PPEs and psychological support are associated with reasons for increased risk perception. $^{40,41}$

Moreover, international students' comparatively higher anxiety levels suggest that the resources offered to international students are inadequate in allaying their fears or anxieties concerning COVID-19. In other words, international students may have had adequate material resources (eg, staying in a hostel, available food, adequate protective equipment) but may have lacked quality social interaction apart from online activities due to the COVID-19 restrictions. These restrictions in addition to the added pressure of being an international student as well as indications that the COVID-19 pandemic may continue for some time may have made them anxious. This is consistent with the diathesis-stress model which postulates that stress in any form has the ability to trigger predisposed illness and (in the present study) anxiety. ${ }^{27,42}$ This is also possible when ineffective or maladaptive coping strategies are used to deal with the stressors according to the transactional model of stress and coping. ${ }^{43}$

The comparable levels of perceived satisfaction with support, information seeking, and suicidal ideation between the groups indicates that the students were equally satisfied with the support being offered (from the university, families, and friends), and equally informed regarding COVID-19 (from internet, university, friends, and news media) which may have made them feel less suicidal. This is reassuring because it may help reduce frustrations that students may experience. $^{22,32}$ This concurs with the transactional model of stress and coping which asserts that an appropriately adaptive coping strategy has the ability to mitigate stressors/challenges that may have exceeded the personal resources of the individual thereby preventing a mental health disorder, ${ }^{43}$ and with respect to the present study, suicide. Adequate information concerning COVID-19 has also been associated with better coping strategies which subsequently help the individual's health. ${ }^{21}$ This supports other previous studies which have reported higher association between positive social support/activities and good mental health. ${ }^{19,36}$

In addition, staying with family members, perceived satisfaction with support, and information seeking were the factors that predicted anxiety among international students. This suggested that staying with family members may help reduce anxiety among international students. Also, adequate support and information are needed to deal with the increasing anxiety of international students. However, information seeking was the only factor that predicted local students' anxiety. This suggests that more information is needed to deal with the increasing anxiety among local students. These findings support a previous study showing that compared with Thai and Indonesian students, Taiwanese university students were more negatively affected by COVID-19 information from the internet and medical staff. ${ }^{19}$ This confirms that clear and direct information is needed to allay fear and anxiety among individuals. This is similar to other previous studies that associated these factors with other mental health conditions. ${ }^{34,40}$

Furthermore, staying with family members, perceived susceptibility to COVID-19, and perceived sufficiency with resources were the factors that predicted suicidal ideation 
among international students. These findings suggest that higher perceived susceptibility to COVID-19 was associated with increased suicidal ideation but staying with family members and more resources were needed to deal with increasing suicidal ideation. Social support may be able to mitigate COVID-19 challenges and thereby manage suicidal ideation among international students. ${ }^{43}$ On the other hand, being a male and perceived satisfaction with support were the factors that predicted suicidal ideation among local students. More specifically, being a male and being satisfied with support was associated with reduced suicidal ideation among local students. Therefore, health experts may apply these findings to help improve the mental health of students. The findings indicated that local and international students had significantly different factors that predicted their suicidal ideation.

\section{Limitations}

There are some limitations to the study. First, the present study used university students and therefore the findings may not be generalized to other types of student (eg, primary school children) or individuals who do not receive any formal education. Second, the present study used a cross-sectional design, a design that only provides associations between variables but not causation. Future studies should use a longitudinal study design to strengthen the evidence regarding causal relationships. Third, different countries have different reactions and policies to control COVID-19 infection and so replication may be needed to help understand how the variables used in this present study relate to other countries. Finally, the translation used in the present study was not a standard procedure. Therefore, the linguistic validity between the English and Chinese surveys cannot be guaranteed as being equivalent. Consequently, the internal consistency values found in the present study were somewhat questionable (ie, the highest value was 0.76 and the lowest value was 0.61 ).

\section{Conclusion}

This novel study indicated that local students had higher perceived susceptibility to COVID-19 but decreased perceived sufficiency with resources and anxiety compared with international students in Taiwan. Moreover, the factors that predicted anxiety were different between international and local students in Taiwan. More specifically, staying with family members, perceived satisfaction with support, and information seeking were the factors that predicted anxiety among international students while information seeking was the only factor that predicted local students' anxiety. Furthermore, staying with family members, perceived susceptibility to COVID-19, and perceived sufficiency with resources were the factors that predicted suicidal ideation among international students while being a male and perceived satisfaction with support were the factors that predicted suicidal ideation among local students. Overall, international students seem to have different needs and psychological states during COVID-19 pandemic compared with local students. Hence, university authorities (and to an extent, healthcare workers and family members) may have to pay attention to the peculiar needs of each of these group of students in order to offer tailored support to them.

\section{Acknowledgments}

We thank all the participants for participating in the present study. This study was supported in part by a research grant from the Ministry of Science and Technology, Taiwan (MOST109-2327-B-006-005), in part by a research grant from the Taipei Municipal Wanfang Hospital Cross-Institutions Fund (110-swf-01), and in part by the 2020 Southeast and South Asia and Taiwan Universities Joing Research Scheme (NCKU 33).

\section{Disclosure}

The authors report no conflicts of interest in this work.

\section{References}

1. World Health Organisation. COVID-19 weekly operational update on COVID-19-1; 2021. Available from: https://www.who.int/publications/ $\mathrm{m} /$ item/weekly-operational-update-on-covid-19-1-february-2021. Accessed February 2, 2021.

2. Nicola M, Alsafi Z, Sohrabi C, et al. The socio-economic implications of the coronavirus pandemic (COVID-19): a review. Int $J$ Surg. 2020;78:185-193. doi:10.1016/j.ijsu.2020.04.018

3. Gössling S, Scott D, Hall CM. Pandemics, tourism and global change: a rapid assessment of COVID-19. J Sustain Tour. 2020;1-20. doi:10.1080/09669582.2020.1758708

4. Rajabimajd N, Alimoradi Z, Griffiths MD. Impact of COVID-19related fear and anxiety on job attributes: a systematic review. Asian J Soc Health Behav. 2021;4:51-55. doi:10.4103/shb.shb_24_21

5. Chen I-H, Chen C-Y, Pakpour AH, Griffiths MD, Lin C-Y. Internetrelated behaviors and psychological distress among schoolchildren during COVID-19 school suspension. J Am Acad Child Adolesc Psychiatry. 2020;59(10):1099-1102.e1. doi:10.1016/j. jaac.2020.06.007

6. Balanzá-Martínez V, Atienza-Carbonell B, Kapczinski F, De Boni RB. Lifestyle behaviours during the COVID-19-time to connect. Acta Psychiatr Scand. 2020;141:399-400. doi:10.1111/acps.13177

7. Lin C-Y. Social reaction toward the 2019 novel coronavirus (COVID-19). Editorial. Soc Health Behav. 2020;3(1):1-2. doi:10.4103/shb.Shb_11_20

8. Ahorsu DK, Imani $\bar{V}$, Lin C-Y, et al. Associations between fear of COVID-19, mental health, and preventive behaviours across pregnant women and husbands: an actor-partner interdependence modelling. Int $J$ Ment Health Addict. 2020;1-15. doi:10.1007/s11469-02000340-x. 
9. Choi EPH, Hui BPH, Wan EYF. Depression and anxiety in Hong Kong during COVID-19. Int J Environ Res Public Health. 2020;17(10):3740. doi:10.3390/ijerph17103740

10. Olashore AA, Akanni OO, Fela-Thomas AL, Khutsafalo K. The psychological impact of COVID-19 on health-care workers in African Countries: a systematic review. Asian J Soc Health Behav. 2021;4:85-97. doi:10.4103/shb.shb_32_21

11. Sharma R, Bansal P, Chhabra M, Bansal C, Arora M. Severe acute respiratory syndrome coronavirus-2-associated perceived stress and anxiety among Indian medical students: a cross-sectional study. Asian J Soc Health Behav. 2021;4:98-104. doi:10.4103/shb.shb_9_21

12. Patil ST, Datar MC, Shetty JV, Naphade NM. Psychological consequences and coping strategies of patients undergoing treatment for COVID-19 at a tertiary care hospital: a qualitative study. Asian J Soc Health Behav. 2021;4:62-68. doi:10.4103/shb.shb_5_21

13. Amin KP, Griffiths MD, Dsouza DD. Online gaming during the COVID-19 pandemic in India: strategies for work-life balance. Int $J$ Ment Health Addict. 2020;1-7. doi:10.1007/s11469-020-00358-1

14. Ko C-H, Yen J-Y. Impact of COVID-19 on gaming disorder: monitoring and prevention. $J$ Behav Addict. 2020;9(2):187-189. doi: $10.1556 / 2006.2020 .00040$

15. Ahorsu DK, Lin C-Y, Pakpour AH. The association between health status and insomnia, mental health, and preventive behaviors: the mediating role of fear of COVID-19. Gerontol Geriatr Med. 2020;6:2333721420966081. doi:10.1177/2333721420966081

16. Fazeli S, Mohammadi Zeidi I, Lin C-Y, et al. Depression, anxiety, and stress mediate the associations between internet gaming disorder, insomnia, and quality of life during the COVID-19 outbreak. Addict Behav Rep. 2020;12:100307. doi:10.1016/j.abrep.2020.100307

17. Son C, Hegde S, Smith A, Wang X, Sasangohar F. Effects of COVID-19 on college students' mental health in the United States: interview survey study. J Med Internet Res. 2020;22(9):e21279. doi: $10.2196 / 21279$

18. Seetan K, Al-Zubi M, Rubbai Y, Athamneh M, Khamees A, Radaideh T. Impact of COVID-19 on medical students' mental wellbeing in Jordan. PLoS One. 2021;16(6):e0253295. doi:10.1371/journal.pone.0253295

19. Pramukti I, Strong C, Sitthimongkol Y, et al. Anxiety and suicidal thoughts during the COVID-19 pandemic: cross-country comparative study among Indonesian, Taiwanese, and Thai university students. J Med Internet Res. 2020;22(12):e24487. doi:10.2196/24487

20. Muse K, McManus F, Leung C, Meghreblian B, Williams JM. Cyberchondriasis: fact or fiction? A preliminary examination of the relationship between health anxiety and searching for health information on the Internet. $J$ Anxiety Disord. 2012;26(1):189-196. doi:10.1016/j.janxdis.2011.11.005

21. Huang P-C, Hung C-H, Kuo Y-J, et al. Expanding protection motivation theory to explain willingness of COVID-19 vaccination uptake among Taiwanese university students. Vaccines. 2021;9(9):1046. doi: $10.3390 /$ vaccines9091046

22. Lin M, Cheng Y. Policy actions to alleviate psychosocial impacts of COVID-19 pandemic: experiences from Taiwan. Soc Health Behav. 2020;3(2):72. doi:10.4103/shb.shb_18_20

23. Abdullah I. COVID-19: threat and fear in Indonesia. Psychol Trauma. 2020;12(5):488-490. doi:10.1037/tra0000878

24. Ahorsu DK, Adjaottor ES, Yeboah FA, Opoku Y. Mental health challenges in academia: comparison between students of the various educational levels in Ghana. J Ment Health. 2021;30(3):292-299. doi:10.1080/09638237.2020.1739253

25. Pedrelli P, Nyer M, Yeung A, Zulauf C, Wilens T. College students: mental health problems and treatment considerations. Acad Psychiatry. 2015;39(5):503-511. doi:10.1007/s40596-014-0205-9

26. Aucejo EM, French J, Ugalde Araya MP, Zafar B. The impact of COVID-19 on student experiences and expectations: evidence from a survey. J Public Econ. 2020;191:104271. doi:10.1016/j. jpubeco.2020.104271
27. Rodríguez-Hidalgo AJ, Pantaleón Y, Dios I, Falla D. Fear of COVID-19, stress, and anxiety in university undergraduate students: a predictive model for depression. Front Psychol. 2020;11:591797. doi:10.3389/fpsyg.2020.591797

28. Morales-Rodríguez FM. Fear, stress, resilience and coping strategies during COVID-19 in Spanish university students. Sustainability. 2021;13(11):5824. doi:10.3390/su13115824

29. Martinez-Libano J, Cabrera MMY. Suicidal ideation and suicidal thoughts in university students during the covid-19 pandemic: a systematic review. Revista Argentina de Clínica Psicológic. 2021;30(2):390-405. doi:10.24205/03276716.2020.4038

30. Taiwan Centers for Disease Control. COVID-19 (2019-nCoV). Available from: https://sites.google.com/cdc.gov.tw/2019-ncov/tai wan. Accessed February 2, 2021.

31. Pakpour AH, Liu C-H, Hou W-L, et al. Comparing fear of COVID-19 and preventive COVID-19 infection behaviors between Iranian and Taiwanese older people: early reaction may be a key. Front Public Health. 2021. doi:10.3389/fpubh.2021.740333

32. Wang CJ, Ng CY, Brook RH. Response to COVID-19 in Taiwan: big data analytics, new technology, and proactive testing. JAMA. 2020;323(14):1341-1342. doi:10.1001/jama.2020.3151

33. Chang K-C, Strong C, Pakpour AH, Griffiths MD, Lin C-Y. Factors related to preventive COVID-19 infection behaviors among people with mental illness. J Formos Med Assoc. 2020;119(12):1772-1780. doi:10.1016/j.jfma.2020.07.032

34. Chang K-C, Hou W-L, Pakpour AH, Lin C-Y, Griffiths MD. Psychometric testing of three COVID-19-related scales among people with mental illness. Int $J$ Ment Health Addict. 2020;1-13. doi:10.1007/s11469-020-00361-6

35. Lin M-P. Prevalence of internet addiction during the COVID-19 outbreak and its risk factors among junior high school students in Taiwan. Int $J$ Environ Res Public Health. 2020;17(22):8547. doi:10.3390/ijerph17228547

36. Chen WL, Song SY, Yap KH. The unintended consequences of the pandemic: the new normal for college students in South Korea and Taiwan. Front Public Health. 2021;9:598302. doi:10.3389/ fpubh.2021.598302

37. Liao Q, Cowling BJ, Lam WWT, Ng DMW, Fielding R. Anxiety, worry and cognitive risk estimate in relation to protective behaviors during the 2009 influenza A/H1N1 pandemic in Hong Kong: ten cross-sectional surveys. BMC Infect Dis. 2014;14:169. doi:10.1186/ 1471-2334-14-169

38. Li D-J, Ko N-Y, Chen Y-L, et al. COVID-19-related factors associated with sleep disturbance and suicidal thoughts among the Taiwanese public: a Facebook survey. Int J Environ Res Public Health. 2020;17(12):4479. doi:10.3390/ijerph17124479

39. Chung SK, Long CF. A study of the revised State-Trait Anxiety Inventory. Psychol Test. 1984;31(1):27-36.

40. Lam SC, Arora T, Grey I, et al. Perceived risk and protection from infection and depressive symptoms among healthcare workers in mainland China and Hong Kong during COVID-19. Front Psychiatry. 2020;11:686. doi:10.3389/fpsyt.2020.00686

41. Abdel Wahed WY, Hefzy EM, Ahmed MI, Hamed NS. Assessment of knowledge, attitudes, and perception of health care workers regarding COVID-19, A cross-sectional study from Egypt. J Commun Health. 2020;45(6):1242-1251. doi:10.1007/s10900-020-00882-0

42. Monroe SM, Simons AD. Diathesis-stress theories in the context of life stress research: implications for the depressive disorders. Psychol Bull. 1991;110(3):406-425. doi:10.1037/0033-2909.110.3.406

43. Lazarus RS, Folkman S. Stress, Appraisal, and Coping. Springer; 1984. 


\section{Publish your work in this journal}

Psychology Research and Behavior Management is an international, peer-reviewed, open access journal focusing on the science of psychology and its application in behavior management to develop improved outcomes in the clinical, educational, sports and business arenas. Specific topics covered in the journal include: Neuroscience, memory and decision making; Behavior modification and management; Clinical applications; Business and sports performance management; Social and developmental studies; Animal studies. The manuscript management system is completely online and includes a very quick and fair peer-review system, which is all easy to use. Visit http://www. dovepress.com/testimonials.php to read real quotes from published authors. 